\title{
Article \\ Effects of Varying the Fin Width, Fin Height, Gate Dielectric Material, and Gate Length on the DC and RF Performance of a 14-nm SOI FinFET Structure
}

\author{
Nour El I. Boukortt ${ }^{1, *}$, Trupti Ranjan Lenka ${ }^{2}$, , Salvatore Patanè ${ }^{3}\left(\mathbb{D}\right.$ and Giovanni Crupi ${ }^{4}(\mathbb{C}$ \\ 1 Electronics and Communication Engineering Department, Kuwait College of Science and Technology, Doha \\ District 4, Doha 13113, Kuwait \\ 2 Electronics and Communication Engineering Department, National Institute of Technology Silchar, \\ Cachar 788010, Assam, India; trlenka@ieee.org \\ 3 Dipartimento di Scienze Matematiche e Informatiche, Scienze Fisiche e Scienze Della Terra, University of \\ Messina, 98166 Messina, Italy; patanes@unime.it \\ 4 BIOMORF Department, University of Messina, 98125 Messina, Italy; crupig@unime.it \\ * Correspondence: n.boukortt@kcst.edu.kw
}

check for

updates

Citation: Boukortt, N.E.I.; Lenka, T.R.; Patanè, S.; Crupi, G. Effects of Varying the Fin Width, Fin Height, Gate Dielectric Material, and Gate Length on the DC and RF Performance of a 14-nm SOI FinFET Structure. Electronics 2022, 11, 91.

https://doi.org/10.3390/

electronics11010091

Academic Editors: Tieshan Yang and Sanshui Xiao

Received: 14 November 2021

Accepted: 26 December 2021

Published: 28 December 2021

Publisher's Note: MDPI stays neutral with regard to jurisdictional claims in published maps and institutional affiliations.

Copyright: (C) 2021 by the authors. Licensee MDPI, Basel, Switzerland. This article is an open access article distributed under the terms and conditions of the Creative Commons Attribution (CC BY) license (https:// creativecommons.org/licenses/by/ $4.0 /)$.

\begin{abstract}
The FinFET architecture has attracted growing attention over the last two decades since its invention, owing to the good control of the gate electrode over the conductive channel leading to a high immunity from short-channel effects (SCEs). In order to contribute to the advancement of this rapidly expanding technology, a 3D 14-nm SOI n-FinFET is performed and calibrated to the experimental data from IBM by using Silvaco TCAD tools. The calibrated TCAD model is then investigated to analyze the impact of changing the fin width, fin height, gate dielectric material, and gate length on the DC and RF parameters. The achieved results allow gaining a better understanding and a deeper insight into the effects of varying the physical dimensions and materials on the device performance, thereby enabling the fabrication of a device tailored to the given constraints and requirements. After analyzing the optimal values from different changes, a new device configuration is proposed, which shows a good improvement in electrical characteristics.
\end{abstract}

Keywords: FinFET; gate-length downscaling; high-k gate dielectric; RF parameters; SOI; TCAD simulation

\section{Introduction}

The structure of the fin field-effect transistor (FinFET) has completely emerged as a promising design solution for CMOS logic and memory circuit design because of its good immunity to short channel effects (SCEs) [1-3]. This technology enables the creation of high-performance ultra-scaled, high-density integration, and high-performance silicon (Si) chips [1-4]. In the silicon industry, device miniaturization is still considered a key feature to achieve better short-channel performance. Currently, a great effort concerns the development of FinFET devices with dimensions below $5 \mathrm{~nm}$ that represent the target in the near future [4-8]. Despite the effort made to create devices with dimensions below $5 \mathrm{~nm}$, many aspects still remain to be clarified and optimized, also with a view to a larger-scale application of the devices.

This paper presents an investigation of 3D 14-nm FinFET on thin silicon on insulator (SOI) wafer using Silvaco tools. The SOI technology shows significantly large improvement compared to the previous FinFET technology. For better Si channel controllability, hafnium oxide $\left(\mathrm{HfO}_{2}\right)$ was used to cover the $\mathrm{Si}$ channel as a gate dielectric. The impact of varying the fin width $\left(W_{\text {fin }}=4,6.5,15\right.$, and $\left.20 \mathrm{~nm}\right)$, fin height $\left(H_{\text {fin }}=10,15,20,25,30\right.$, and $\left.35 \mathrm{~nm}\right)$, gate dielectric materials $\left(\mathrm{TiO}_{2}, \mathrm{La}_{2} \mathrm{O}_{3}, \mathrm{HfO}_{2}, \mathrm{Al}_{2} \mathrm{O}_{3}, \mathrm{Si}_{3} \mathrm{~N}_{4}\right.$, and $\left.\mathrm{SiO}_{2}\right)$, and gate length $\left(L_{g}=5,10,15\right.$, and $\left.20 \mathrm{~nm}\right)$ on the DC and RF performance of the considered structure is carefully analyzed and discussed. The analysis is performed by investigating the following 
parameters: threshold voltage $\left(V_{t h}\right)$, subthreshold slope $(S S)$, drain-induced barrier lowering $(D I B L)$, on-state current $\left(I_{o n}\right)$, off-state current $\left(I_{\text {off }}\right), I_{\text {on }} / I_{\text {off }}$ ratio, transconductance $\left(g_{m}\right)$, gate capacitance $\left(C_{g g}\right)$, and cut-off frequency $\left(f_{T}\right)$. The development of a comparative analysis enables gaining a better understanding of how to improve device performance, depending on the given fabrication constraints and application requirements.

It should be underlined that the great interest in the FinFET technology is witnessed by the many papers that have been published over the years to investigate the FinFET performance by using both TCAD simulations [8-13] and measurements [14-18]. Although a measurement-based investigation is a mandatory step prior to the use of a device in real applications, the TCAD simulation is considered a powerful and costless type of analysis to optimize device performance. This is because the TCAD tool allows predicting how the device performance changes by varying the design parameters without the need for time-consuming and costly experiments [13].

The rest of this paper is structured as follows: Section 2 presents the device structure, Section 3 describes the developed model for the achieved simulations, Section 4 reports and discusses the obtained findings; and the last section concludes the paper.

\section{Device Structure}

The 3D 14-nm SOI FinFET device has been simulated using Silvaco TCAD. Figure 1 shows the 3D schematic diagram of the FinFET device with a physical gate length $\left(L_{g}\right)$ of $20 \mathrm{~nm}$. The geometrical parameters and material properties are specified in previously published papers [1-3]. $\mathrm{HfO}_{2}$ is used as a gate dielectric material. The doping densities of the source (n-type), drain (n-type), and covered fin (p-type) region were $1 \times 10^{21} \mathrm{~cm}^{-3}$, $1 \times 10^{21} \mathrm{~cm}^{-3}$, and $1 \times 10^{16} \mathrm{~cm}^{-3}$, respectively. The contact resistance of $1 \times 10^{-9} \Omega . \mathrm{cm}^{2}$ was selected for the source/drain region. Table 1 illustrates the physical parameters of the investigated model.
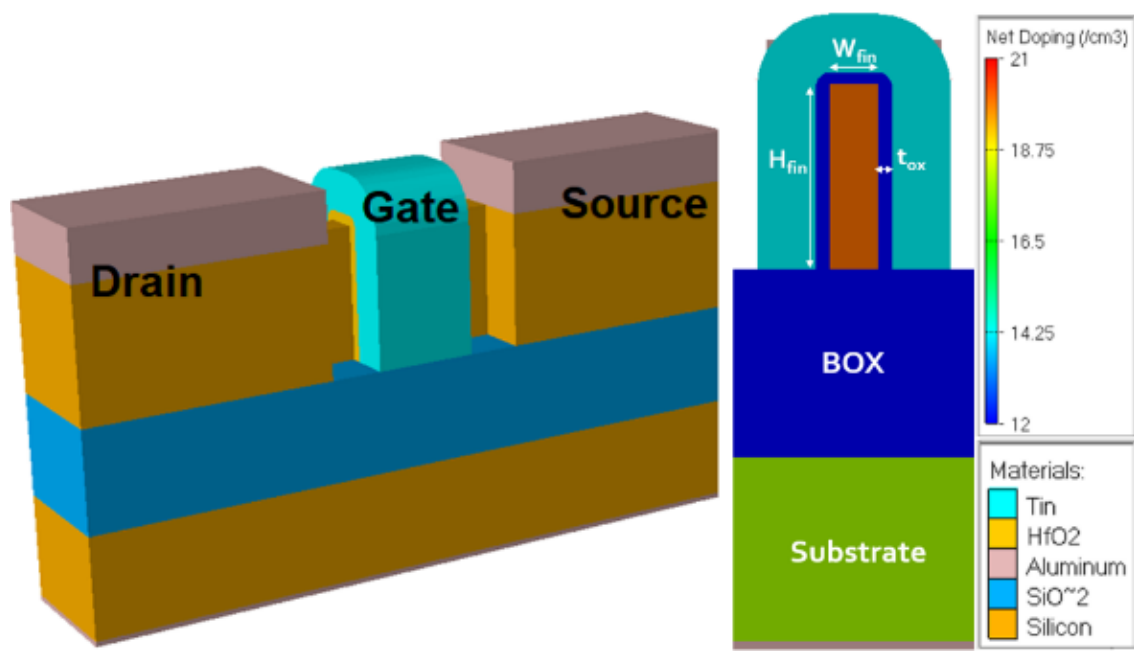

Figure 1. Structure of 3D 14-nm SOI n-FinFET device with a single fin. 
Table 1. Device parameters for a 14-nm n-FinFET.

\begin{tabular}{cc}
\hline Parameters & Values \\
\hline Channel length, $L_{g}$ & $20 \mathrm{~nm}$ \\
Fin height, $H_{\text {fin }}$ & $26 \mathrm{~nm}$ \\
Fin width, $W_{\text {fin }}$ & $6.5 \mathrm{~nm}$ \\
S/D length, $\mathrm{L}_{\mathrm{S} / \mathrm{D}}$ & $50 \mathrm{~nm}$ \\
S/D extension length, $\mathrm{L}_{\mathrm{S} / \mathrm{D}}$ & $7 \mathrm{~nm}$ \\
Buried oxide $\left(\mathrm{SiO}_{2}\right.$ ) thickness, $\mathrm{t}_{\mathrm{BOX}}$ & $50 \mathrm{~nm}$ \\
Gate dielectric $\left(\mathrm{HfO}_{2}\right.$ ) thickness, $\mathrm{t}_{\mathrm{Ox}}$ & $4 \mathrm{~nm}$ \\
Channel doping (boron, p-type), $\mathrm{N}_{\mathrm{ch}}$ & $10^{16} \mathrm{~cm}^{-3}$ \\
S/D doping (arsenic, n-type), $\mathrm{N}_{\mathrm{S} / \mathrm{D}}$ & $10^{21} \mathrm{~cm}^{-3}$ \\
S/D extension doping (arsenic, n-type) & $10^{19} \mathrm{~cm}^{-3}$ \\
Si substrate doping (boron, p-type) & $10^{16} \mathrm{~cm}^{-3}$ \\
Gate work function (TiN (Sn), $\left.\Phi_{\mathrm{m}}\right)$ & $4.32 \mathrm{eV}$ \\
\hline
\end{tabular}

\section{Simulation Model}

For device simulation, CVT, CCSMOB, ANALYTIC, BGN, SRH, and Auger recombination were also included. Fermi-Dirac distribution has been enabled. For quantum confinement, the BQP model was considered [13]. By considering a FinFET device based on using one single fin, the effective channel width can be estimated as follows

$$
W_{\text {eff }}=2 H_{f i n}+W_{f i n}
$$

where $H_{\text {fin }}$ is the fin height and $W_{f i n}$ is the fin width.

The electron $(n)$ and hole $(p)$ densities with BQP equation can be expressed by [13]

$$
\begin{gathered}
n=N_{c} \mathrm{e}^{-\frac{\left(E_{c}+q \mathrm{Q}\right)}{\mathrm{k} T_{L}}} \\
p=N_{v} \mathrm{e}^{-\frac{\left(\mathrm{qQ}-\mathrm{E}_{\mathrm{V}}\right)}{\mathrm{k} T_{L}}} \\
Q=\frac{-h^{2}}{2} \frac{\gamma \underline{\nabla}\left(M^{-1} \underline{\nabla}\left(n^{\alpha}\right)\right)}{n^{\alpha}}
\end{gathered}
$$

$N_{c}$ and $N_{v}$ are the effective density of states for electrons and holes, respectively. $E_{c}$ and $E_{v}$ are the conduction and valence bands, respectively. $\mathrm{k}$ is the Boltzmann constant, $T_{L}$ is the local lattice temperature, $q$ is the electric charge, $Q$ is the quantum potential, $M^{-1}$ is the inverse effective mass tensor, and $\gamma$ and $\alpha$ are two adjustable parameters.

\section{Device Validation}

Initially, the investigated 14-nm SOI n-FinFET model was carefully calibrated according to the experimental data in [1]. In order to match the simulated I-V curves with the experimental data from IBM [1], some physical parameters such as the doping density, thickness, source/drain extension length, and gate work function were carefully adjusted. Figure 2 illustrates simulated I-V characteristics at two different values of $V_{d s}: 0.05 \mathrm{~V}$ (linear) and $0.8 \mathrm{~V}$ (saturation). I-V model curves exactly match with the experimental as is observed at both bias conditions. The device characteristics of the investigated model are compared to the experimental outputs [1] and presented in Table 2. To further validate the developed model, the simulation results were compared also to Sun's work [2]. Figure 3 presents the output I-V characteristics of the investigated model at different gate-source voltages. Figure 3 shows a non-zero current for $V_{g s}$ just above $V_{t h}$ and the increase in $I_{d s}$ with increasing input voltage $V_{g s}$. 


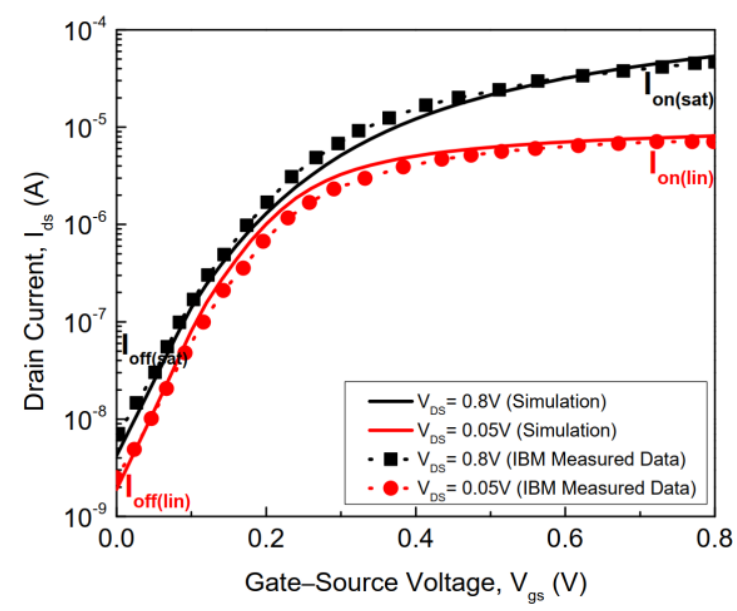

Figure 2. Simulation and experimental I-V curves of the investigated FinFET model [1].

Table 2. Characteristics for the investigated FinFET model.

\begin{tabular}{cccc}
\hline $\begin{array}{c}\text { Device } \\
\text { Characteristics }\end{array}$ & This Work & Ref. [1] & Ref. [2] \\
\hline$V_{d d}(\mathrm{mV})$ & 800 & 800 & 800 \\
$V_{\text {th } \text { lin }}(\mathrm{mV})$ & 137 & - & 162 \\
$V_{\text {th, sat }}(\mathrm{mV})$ & 120 & - & 147 \\
$I_{\text {on }, \text { lin }}(\mu \mathrm{A})$ & 8.11 & - & 7.64 \\
$I_{\text {on, sat }}(\mu \mathrm{A})$ & 53.6 & 2.51 & 58.15 \\
$I_{\text {off, lin }}(\mathrm{nA})$ & 1.89 & - & 1.43 \\
$I_{\text {off, sat }}(\mathrm{nA})$ & 4.22 & - & 2.51 \\
$I_{\text {on, } \text { lin }} / I_{\text {off, lin }}$ & $4.29 \times 10^{3}$ & - & $5.32 \times 10^{3}$ \\
$I_{\text {on, sat }} / I_{\text {off, sat }}$ & $1.27 \times 10^{4}$ & 67 & $2.32 \times 10^{4}$ \\
$S S_{\text {lin }}(\mathrm{mV} / \mathrm{dec})$ & 61 & - & 62.83 \\
$S S_{\text {sat }}(\mathrm{mV} / \mathrm{dec})$ & 64.91 & 55 & 63.45 \\
$D I B L(\mathrm{mV} / \mathrm{V})$ & 43.32 & & 20.5 \\
\hline
\end{tabular}

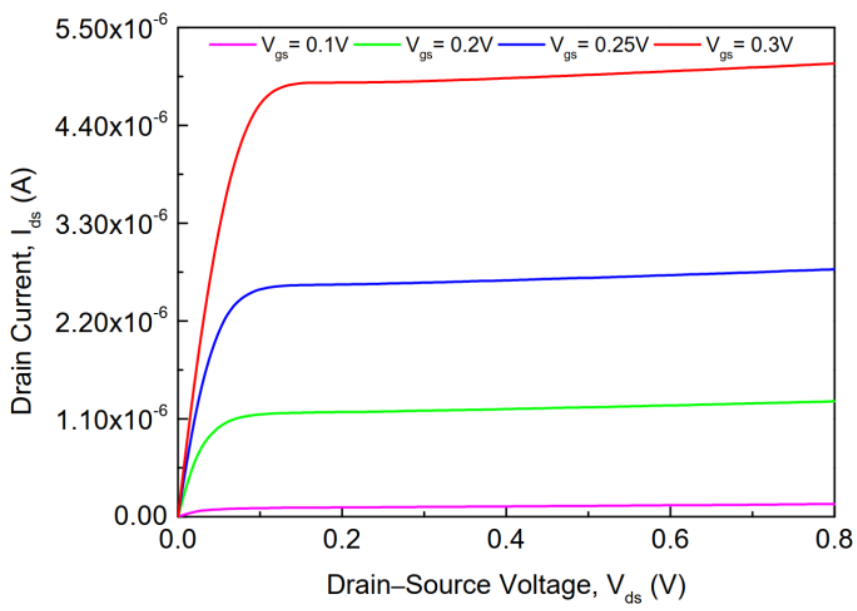

Figure 3. Output I-V curves of the investigated FinFET model with different gate-source voltages.

To evaluate the SCEs, the subthreshold slope (SS) and drain-induced barrier lowering $(D I B L)$ are extracted as follows $[4,11]$

$$
S S=\frac{d\left(V_{g s}\right)}{d\left[\log \left(I_{d s, s a t}\right)\right]}
$$




$$
D I B L=\frac{\left|V_{t h, \text { sat }}-V_{t h, \text { lin }}\right|}{V_{D D}-0.05 \mathrm{~V}}
$$

where $V_{g s}$ is the gate-source voltage and $I_{d s, s a t}$ is the drain current (under saturated biasing condition). $V_{\text {th }}$ sat and $V_{\text {th }}$,in are the threshold voltages under saturated and linear conditions, respectively. The values of $S S$ and DIBL are, respectively, $61 \mathrm{mV} / \mathrm{dec}$ and $43.32 \mathrm{mV} / \mathrm{V}$ for the 14-nm n-FinFET. These parameters are approximately maintained the same as the ones reported in papers [1-4].

The cut-off frequency $\left(f_{T}\right)$ is considered as a crucial RF parameter which defines the speed response of the RF circuit design. The $f_{T}$ can be expressed by [14-17]

$$
f_{T}=\frac{g_{m}}{2 \pi C_{g g}}=\frac{g_{m}}{2 \pi\left(C_{g S}+C_{g d}\right)}
$$

where $g_{m}$ is the transconductance, $C_{g g}$ is the total gate capacitance, $C_{g s}$ is the gate-source capacitance, and $C_{g d}$ is the gate-drain capacitance.

\section{Results and Discussion}

In this section, the effects of changing the fin width, the fin height, the gate dielectric material, and the gate length on the device performance are analyzed and investigated for the SOI FinFET structure under study. The investigated tri-gate FinFET device has a 3D channel as illustrated in Figure 1. The model was calibrated with an agreement to IBM's model (see Figure 2). The electrical characteristics of the FinFET device are evaluated at a room temperature of $300 \mathrm{~K}$.

\subsection{Effects of the Fin Width/Height on Device Performance}

In this study, it is important to start by investigating the effect of different fin size ratios on device characteristics. To analyze the impact of the fin width on the device performance, the fin width of the studied structure was varied from $4 \mathrm{~nm}$ to $20 \mathrm{~nm}$ with the fin height kept fixed at $26 \mathrm{~nm}$. It should be underlined that, although a larger fin width allows enlarging the total gate width (see Equation (1)), when the gate length shrinks, the $W_{\text {fin }}$ width has to shrink as well in order to maintain an efficient suppression of the SCEs [19]. Figure 4 reports the effect of changing the fin width on the transfer I-V characteristics and the corresponding transconductance (Triangle symbols) for the investigated device. As can be clearly observed, the increase in the fin width leads to a reduction of the threshold voltage, in agreement with what is expected from previous studies [18]. In addition, owing to the increase of the total gate width (see Equation (1)), a larger fin width implies an increase in the drain current and transconductance $[9,18]$. Figure 5 shows the total gate capacitance versus $V_{g_{s}}$ for the studied device with different values of the fin width. As can be seen, as $V_{g s}$ increases, $C_{g g}$ increases until its value becomes roughly constant [4]. The value of $C_{g g}$ decreases by decreasing the fin width, due to the reduction of the total gate width. Figure 6 shows $f_{T}$ variation as a function of $V_{g s}$ for the studied device with different values of the fin width. The peak in $f_{T}$ increases as $W_{f i n}$ reduces. The behavior of $f_{T}$ is mainly due to the impact of the fin width on $C_{g g}$ rather than on $g_{m}$, as can be observed from Figures 4-6. The peak point of $f_{T}$ is $3.9 \mathrm{THz}$ at $V_{g s}=0.21 \mathrm{~V}$ with a $V_{d s}=0.05 \mathrm{~V}$ for a device with a fin width of $4 \mathrm{~nm}$. 


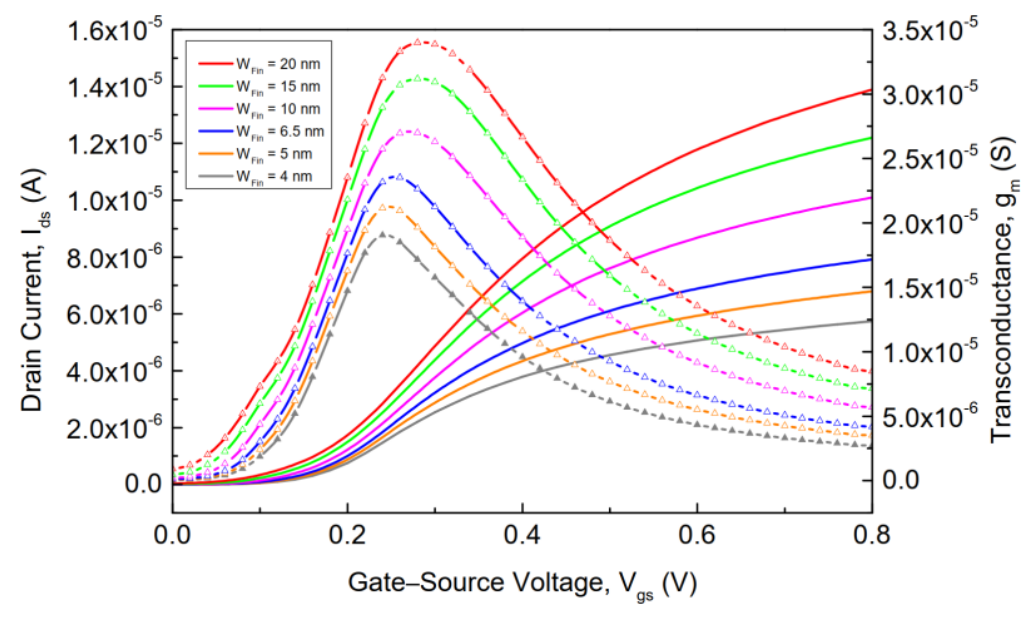

Figure 4. Behavior of the drain current (left axis) and transconductance (Triangle symbols, right axis) versus the gate-source voltage with different values of the fin width at $V_{d s}=0.05 \mathrm{~V}$. The fin height is kept fixed at $26 \mathrm{~nm}$.

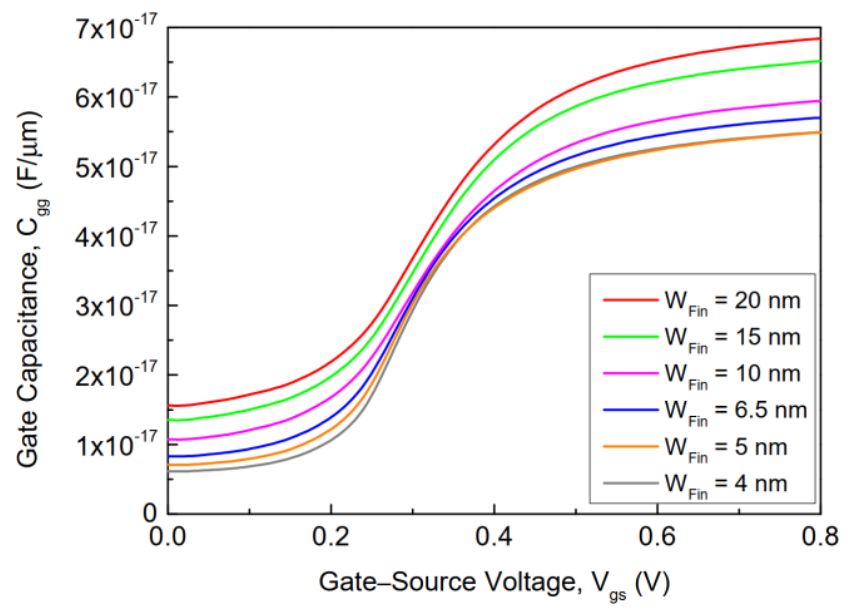

Figure 5. Gate capacitance as a function of gate-source voltage with different values of the fin width at $V_{d s}=0.05 \mathrm{~V}$. The fin height is kept fixed at $26 \mathrm{~nm}$.

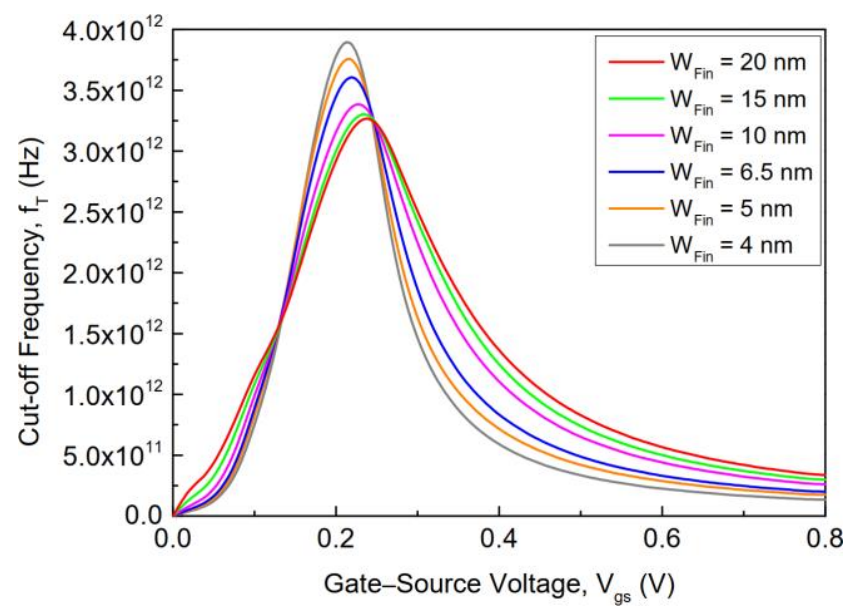

Figure 6. Cut-off frequency as a function of gate-source voltage with different values of the fin width at $V_{d s}=0.05 \mathrm{~V}$. The fin height is kept fixed at $26 \mathrm{~nm}$. 
The variations of the threshold voltage, subthreshold slope, on-current, and off-current with different values of the fin height $\left(H_{\text {fin }}=10,15,20,25,30\right.$, and $\left.35 \mathrm{~nm}\right)$ and of the fin width $\left(W_{\text {fin }}=4,6.5,15\right.$, and $\left.20 \mathrm{~nm}\right)$ are shown in Figures $7-10$, respectively. Figure 7 shows a reduction in the threshold voltage with increasing $H_{f i n}$ and/or $W_{\text {fin }}$. Figure 8 shows the impact of $H_{\text {fin }}$ on the subthreshold slope for FinFET devices with different values of $W_{\text {fin }}$ at $V_{d s}=0.05 \mathrm{~V}$. This figure shows a slight impact of changing $H_{f i n}$ on $S S$ when considering the lower values of the fin width (i.e., $6.5 \mathrm{~nm}$ and $4 \mathrm{~nm}$ ), whereas a marked increase in $S S$ is observed with increasing $H_{\text {fin }}$ and/or $W_{\text {fin }}$ when considering higher values of the fin width. It was observed that, for the studied FinFETs, a smaller fin width leads to better device performance in terms of $S S$. This confirms that studying the impact of varying fin width and fin height is essential for enabling technology development, since they can have a strong impact on the short channel effects. As expected, the increase in the gate width by increasing $H_{f i n}$ and/or $W_{\text {fin }}$ leads to an increase in both on-state current and off-state current, as reported in Figures 9 and 10. Figure 9 shows the impact of $H_{\text {fin }}$ on the switching current $\left(I_{o n}\right)$ for FinFET devices with different $W_{f i n}$ at $V_{g s}=V_{d s}=0.8 \mathrm{~V}$. It is achieved a rapid increase in $I_{o n}$ as $W_{\text {fin }}$ and/or $H_{\text {fin }}$ increase. Figure 10 shows the impact of $H_{\text {fin }}$ on the leakage current $\left(I_{o f f}\right)$ for FinFET devices with different $W_{f i n}$ at $V_{g s}=0 \mathrm{~V}$ and $V_{d s}=0.8 \mathrm{~V}$. It is achieved a clear decrease in $I_{\text {off }}$ as $W_{\text {fin }}$ and/or $H_{\text {fin }}$ decrease. In particular, Figure 10 shows a slighter impact of changing $H_{\text {fin }}$ on $I_{\text {off }}$ when considering the lower values of the fin width (i.e., $6.5 \mathrm{~nm}$ and $4 \mathrm{~nm}$ ), whereas a more marked decrease in $I_{\text {off }}$ is observed with decreasing $H_{\text {fin }}$ and/or $W_{\text {fin }}$ when considering higher values of the fin width. The electrostatic can be improved effectively with shorter fin width, which can report better mitigation of the leakage current for the nanoscale devices. This could be a good design strategy to enhance device performance, but it will be quite difficult to fabricate the pattern on the device with a very high aspect ratio $\left(H_{\text {fin }} / W_{\text {fin }}\right)$. For a given variation in the fin height, the corresponding change in the device performance of the investigated FinFET model can be linked to what was reported and discussed in detail in Kurniawan's work [20].

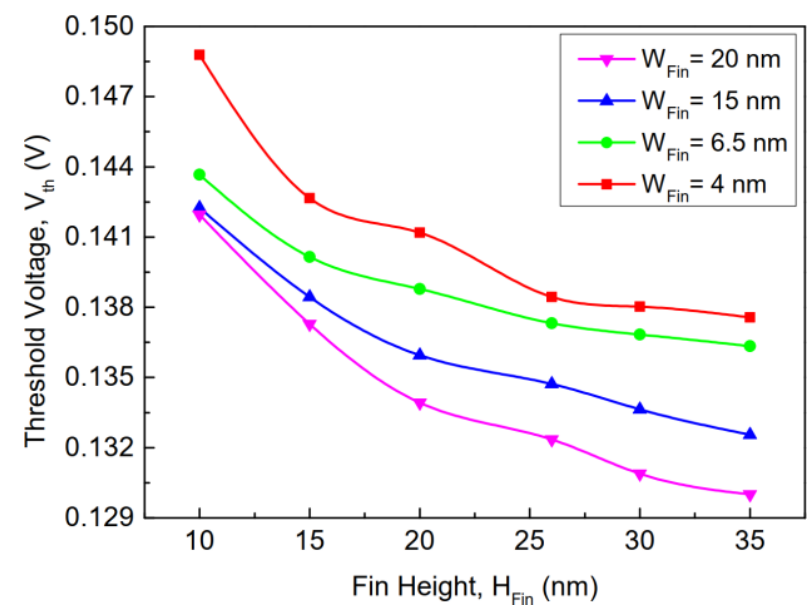

Figure 7. Behavior of the threshold voltage as a function of fin height for FinFET devices with different values of the fin width at $V_{d s}=0.05 \mathrm{~V}$. 


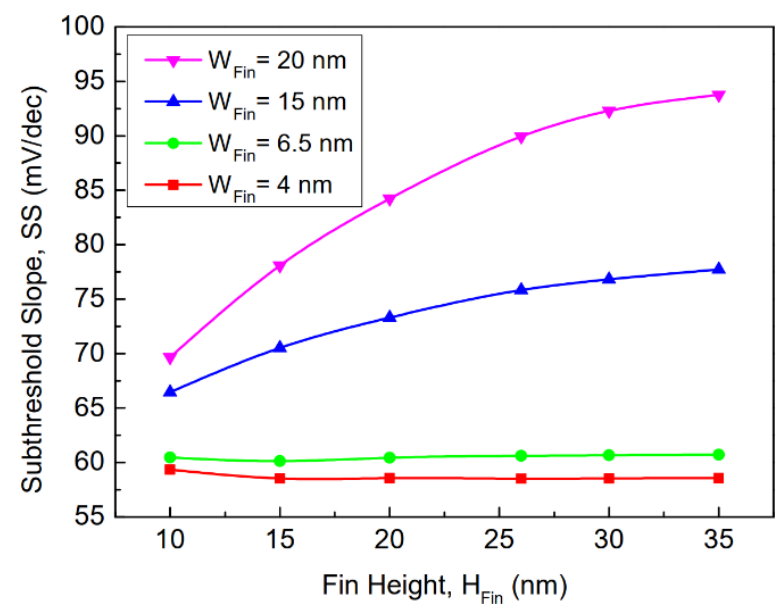

Figure 8. Behavior of the subthreshold slope as a function of fin height for FinFET devices with different values of the fin width at $V_{d s}=0.05 \mathrm{~V}$.

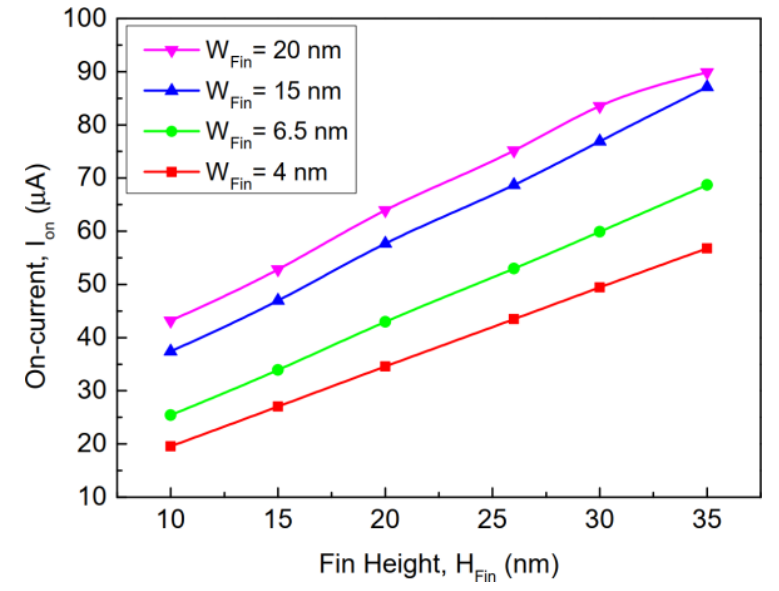

Figure 9. Behavior of the on-current as a function of fin height for FinFET devices with different values of the fin width at $V_{g s}=V_{d s}=0.8 \mathrm{~V}$.

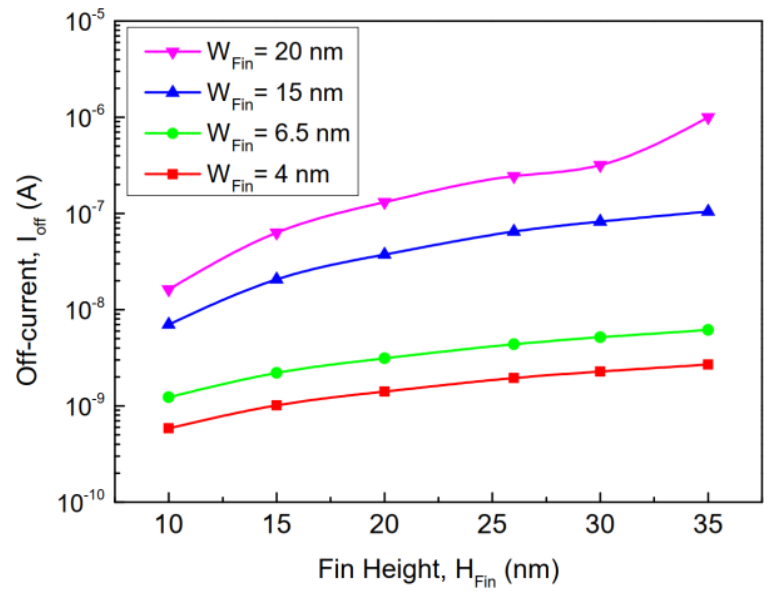

Figure 10. Behavior of the leakage current as a function of fin height for FinFET devices with different values of the fin width at $V_{g s}=0 \mathrm{~V}$ and $V_{d s}=0.8 \mathrm{~V}$.

As is well-known, a higher $I_{o n}$ is well desired while the leakage current $I_{\text {off }}$ should be kept low in order to minimize the static power consumption. Figure 11 shows the effect 
of varying the fin height and the fin width on the $I_{o n} / I_{\text {off }}$ ratio, which is a crucial figure of merit for digital applications. As shown in Figure 11, the $I_{\text {on }} / I_{\text {off }}$ ratio decreases with increasing $H_{\text {fin }}$ and /or $W_{\text {fin }}$. It should be noticed that the highest value of the $I_{\text {on }} / I_{\text {off }}$ ratio occurs at the lowest height of $10 \mathrm{~nm}$ and then decreases approximately exponentially with increasing $H_{\text {fin }}$.

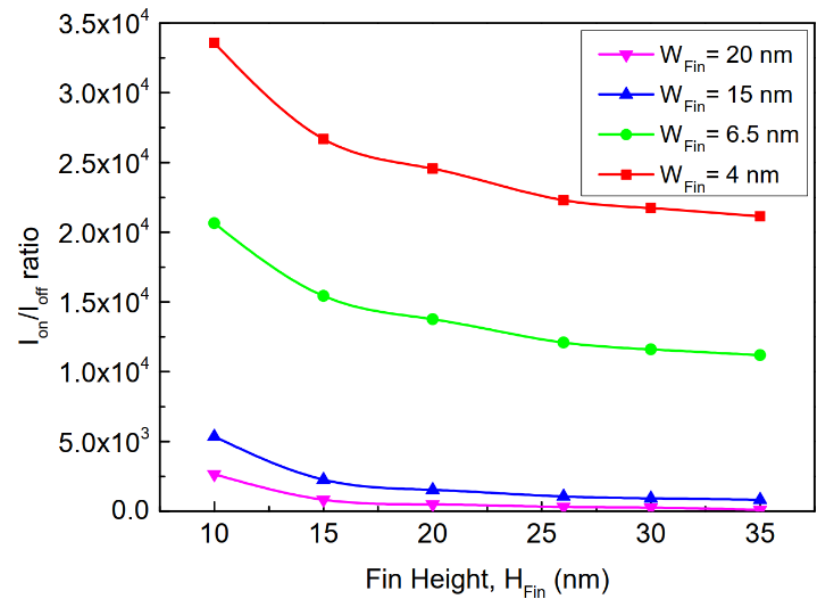

Figure 11. Behavior of the current ratio $I_{o n} / I_{\text {off }}$ as a function of fin height for FinFET devices with different values of the fin width at $V_{d s}=0.8 \mathrm{~V}$.

\subsection{Impact of High-k Dielectric Materials on Device Performance}

To analyze the effect of the gate dielectric materials on the device performance, the fin width, fin height, and gate length of the studied structure were fixed at 6.5, 26, and $20 \mathrm{~nm}$, respectively. Figure 12 shows the total gate capacitance versus $V_{g s}$ for different high-k dielectric materials. Under all of the studied cases, $C_{g g}$ starts increasing as $V_{g s}$ increases until saturation, and then it becomes roughly constant, as expected [4]. The value of $C_{g g}$ increases with high-k dielectric material.

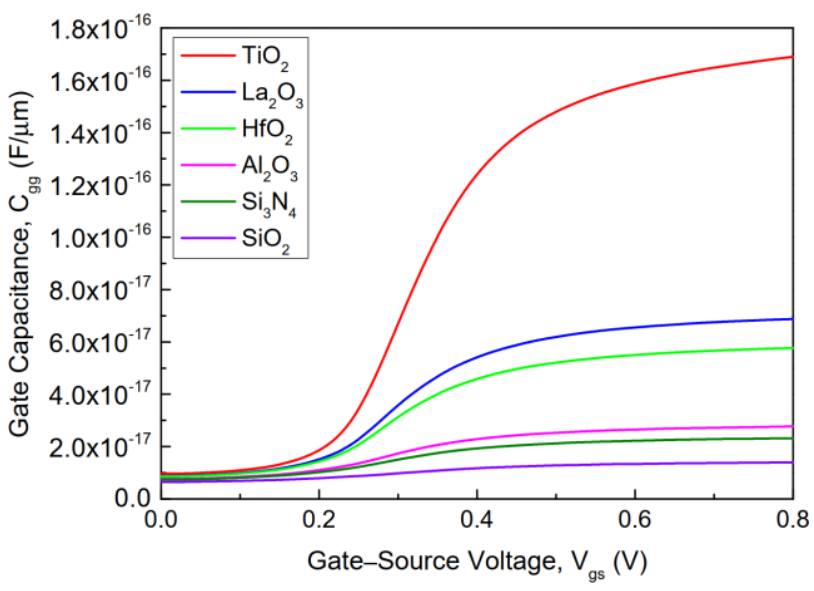

Figure 12. Gate capacitance as a function of gate-source voltage with different gate dielectric materials at $V_{d s}=0.05 \mathrm{~V}$.

The change in transconductance and cut-off frequency with different gate dielectric materials is shown in Figure 13. The analyzed bias point is: $V_{g s}=0.2 \mathrm{~V}$ and $V_{d s}=0.05 \mathrm{~V}$. As can be observed from the figure, a remarkable improvement of the device performance is achieved using higher-k material [4,21]. The value of $g_{m}$ for $\mathrm{TiO}_{2}$ material is higher compared to the values obtained by using the other dielectric materials, implying a higher amplification capability of the device $[4,22]$. The resultant behavior of $f_{T}$ is mainly due to 
the impact of the high-k dielectric material on $\mathrm{g}_{\mathrm{m}}$ rather than on $C_{g g}$, as can be noticed from Figures 12 and 13. The highest $f_{T}$ is obtained at $V_{g s}=0.2 \mathrm{~V}$ with $V_{d s}=0.05 \mathrm{~V}$ for a FinFET model with $\mathrm{TiO}_{2}$ material, reflecting the better gate controllability over the channel fin region and hence higher transconductance.
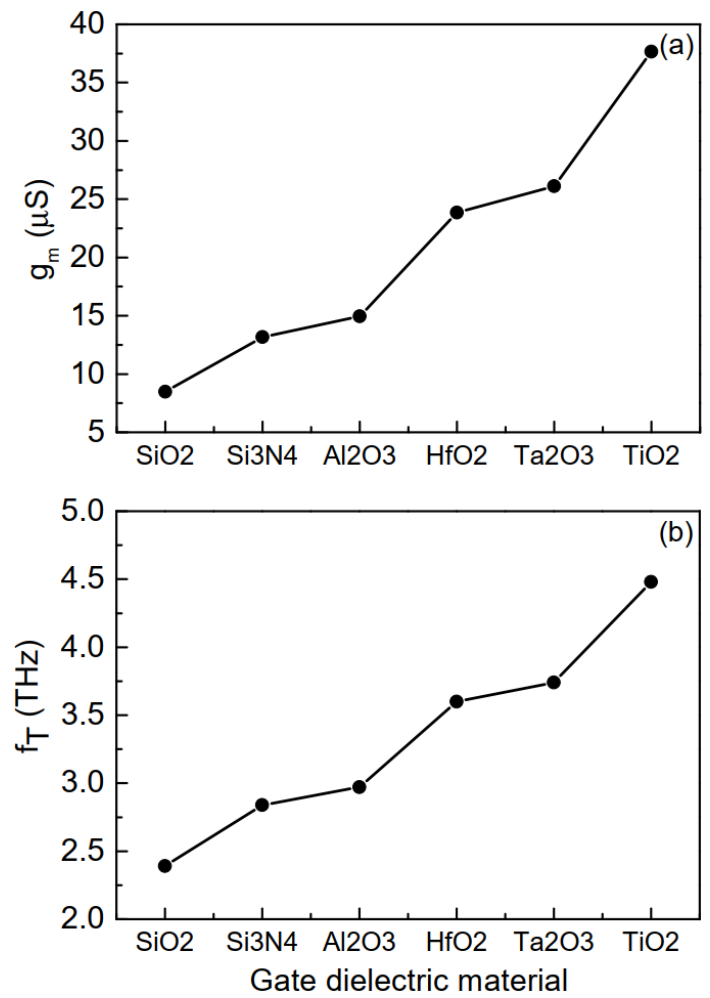

Figure 13. Behavior of (a) transconductance and (b) cut-off frequency with different high-k gate dielectric materials at $V_{d s}=0.05 \mathrm{~V}$.

In short channel devices, the leakage current can be problematic for switching speed in the circuit by leading to an increase in the $I_{\text {on }} / I_{\text {off }}$ ratio. The use of a multigate design structure together with high-k dielectric materials proves good mitigation in device issues and demonstrates high switching speed in electric circuits [16-22]. Figure 14 shows the transfer I-V characteristics in a logarithmic scale of 14-nm SOI n-FinFET under on-state bias conditions $\left(V_{d s}=0.8 \mathrm{~V}\right)$. It is observed that the off-state current decreases, especially with high-k. As expected, using high-k dielectric such as $\mathrm{TiO}_{2}$ is necessary for short channel devices to mitigate the leakage current. It is also observed that the current flow in the short channel can be improved by using high-k dielectric material. As reported in Figure 15, the highest value of $I_{o n} / I_{\text {off }}$ occurs at the highest dielectric constant. For many electronic circuit applications, such as amplifiers and digital circuits, the best $I_{\text {on }} / I_{\text {off }}$ current ratio is at the highest value and therefore it implies better device performance. 


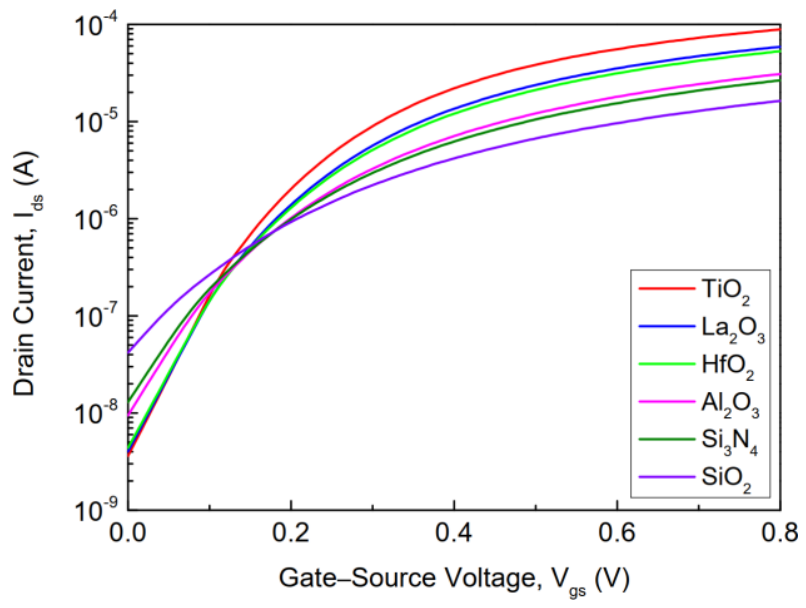

Figure 14. Transfer $\mathrm{I}-\mathrm{V}$ characteristics in logarithmic scale for FinFET devices with different gate dielectric materials at $V_{d s}=0.8 \mathrm{~V}$.

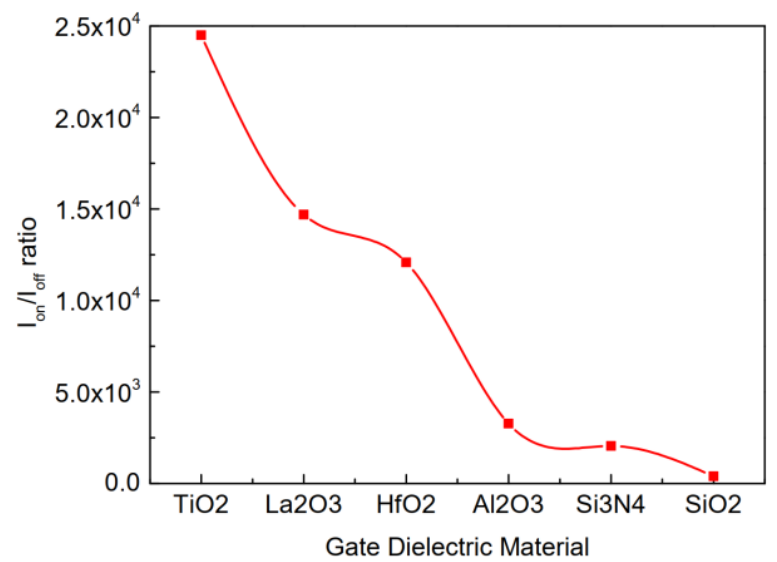

Figure 15. Behavior of the current ratio $I_{o n} / I_{\text {off }}$ as a function of gate dielectric materials for FinFET devices at $V_{d s}=0.8 \mathrm{~V}$.

\subsection{Impact of the Gate Length on Device Performance}

To analyze the effect of the gate length on the device performance, the fin width and fin height of the studied structure were fixed at $6.5 \mathrm{~nm}$ and $26 \mathrm{~nm}$, respectively. Furthermore, the hafnium oxide was used as a gate dielectric material. There are full-node processes for FinFET technologies, such as $16,14,10,7,5$, and $3 \mathrm{~nm}$ in $R \& D$ [1,2]. Thus, is very important to investigate the effect of the gate length on calibrated FinFET device performance. Varying device gate lengths can help in judging the numerical model's accuracy in predicting the device characteristics. The change in transconductance with different gate lengths (from $5 \mathrm{~nm}$ to $20 \mathrm{~nm}$ ) is shown in Figure 16. It can be observed from the figure that a remarkable limitation is achieved by scaling down the gate length. The $g_{m}$ for $10 \mathrm{~nm}$ gate length device reaches higher values compared to other devices with different gate lengths $[4,18]$. The $f_{T}$ behavior is mainly due to the gate length effect on $g_{m}$ rather than on $C_{g g}$, as can be noticed from Figures 16-18. The highest $f_{T}$ is obtained at $V_{g s}=0.25 \mathrm{~V}$ with $V_{d s}=0.05 \mathrm{~V}$ for a device with $5 \mathrm{~nm}$ gate length, as illustrated in Figure 18. To find the effect of the gate length on the device's I-V characteristics, the gate length was varying from $5 \mathrm{~nm}$ to $20 \mathrm{~nm}$. Figure 19 illustrates the effects of the gate length on transfer I-V curves of the device. It is well seen from the figure that reducing the gate length leads to a decrease in the threshold voltage, but it causes an increase in the leakage current (at $V_{g s}=0 \mathrm{~V}$ ). The variation of the threshold voltage, subthreshold slope, and $I_{\text {on }} / I_{\text {off }}$ ratio at two gate lengths with different fin widths is shown in Figures 20-22, respectively. As can be observed, $V_{\text {th }}$ and $S S$ are sensitive to $W_{f i n}$ for a small gate length due to the short channel effect as illustrated in Figures 20 and 21, 
respectively [22-27]. As shown in Figure 22, the highest value of $I_{\text {on }} / I_{\text {off }}$ occurs at the lowest fin width.

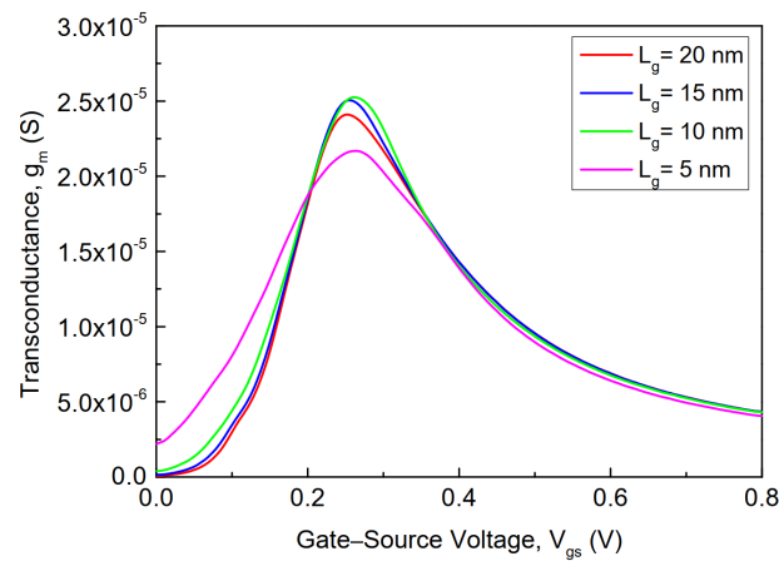

Figure 16. Transconductance as a function of gate-source voltage with different gate lengths at $V_{d s}=0.05 \mathrm{~V}$.

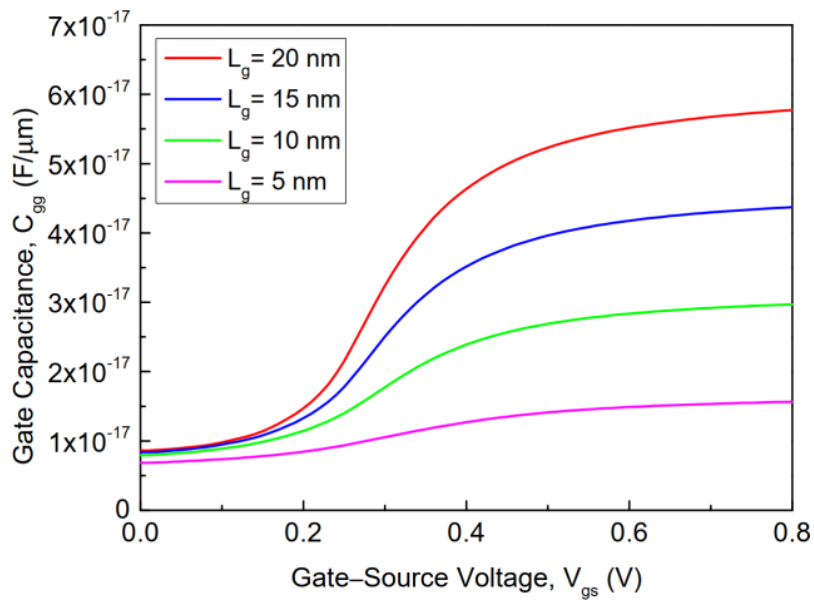

Figure 17. Gate capacitance as a function of gate-source voltage with different gate lengths at $V_{d s}=0.05 \mathrm{~V}$.

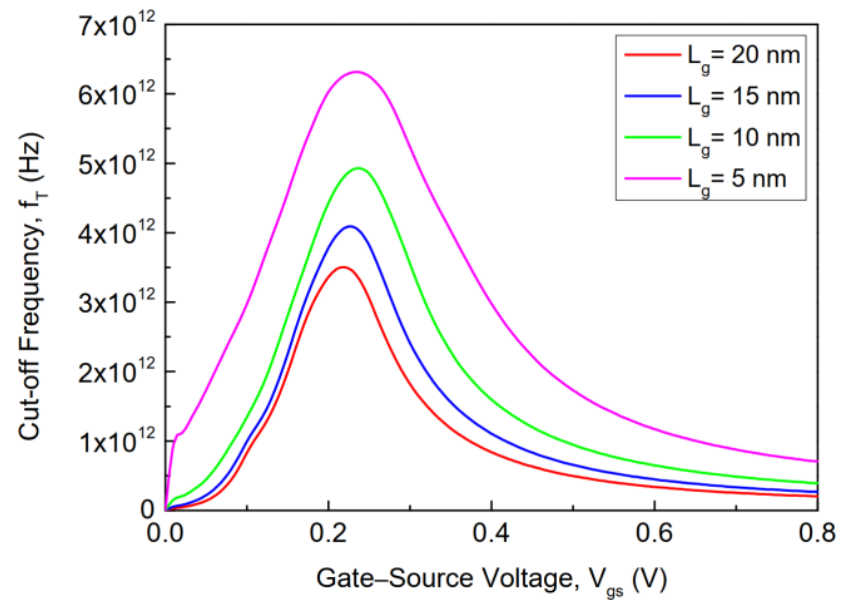

Figure 18. Cut-off frequency as a function of gate-source voltage with different gate lengths at $V_{d s}=0.05 \mathrm{~V}$. 


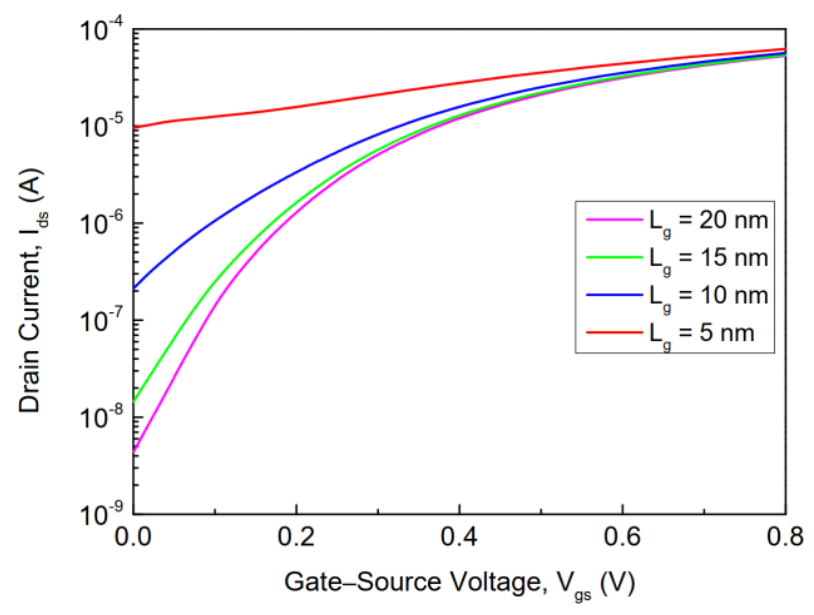

Figure 19. Transfer characteristics logarithmic scale for FinFET devices with different gate lengths at $V_{d s}=0.8 \mathrm{~V}$.

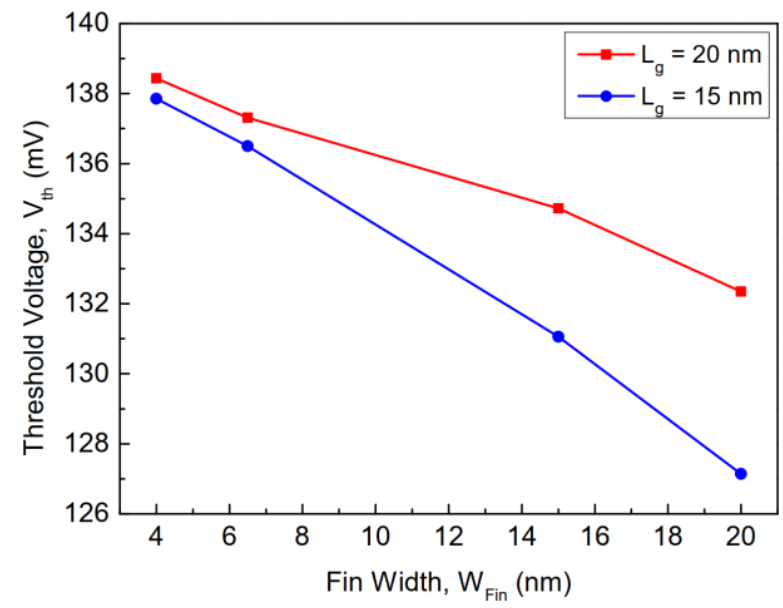

Figure 20. Behavior of the threshold voltage as a function of fin width for FinFET devices with two different gate lengths at $V_{d s}=0.05 \mathrm{~V}$.

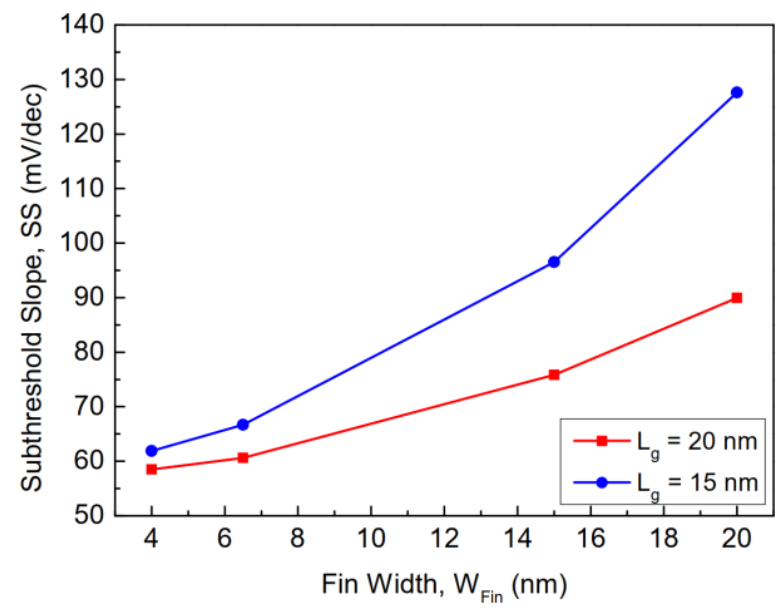

Figure 21. Behavior of the subthreshold slope as a function of fin width for FinFET devices with two different gate lengths at $V_{d s}=0.05 \mathrm{~V}$. 


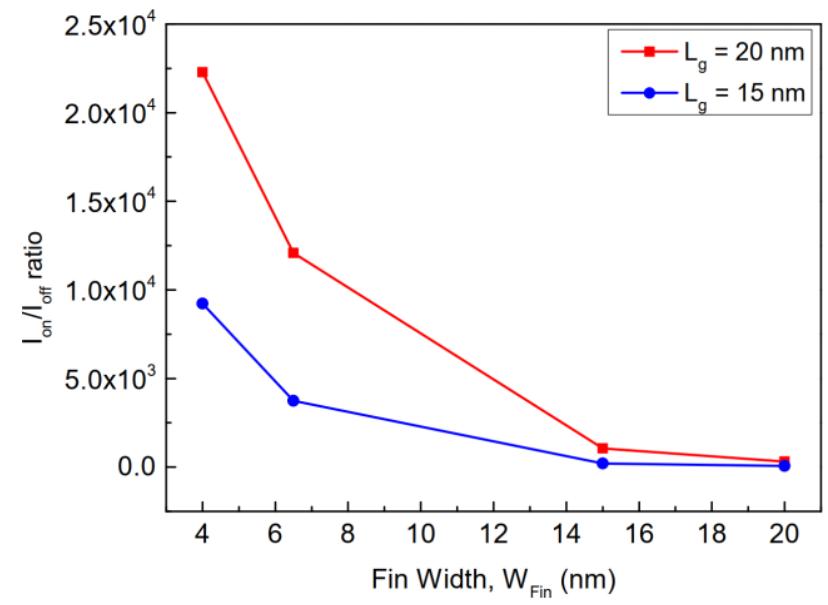

Figure 22. Behavior of $I_{o n} / I_{\text {off }}$ ratio as a function of fin width for FinFET devices with two different gate lengths at $V_{d s}=0.8 \mathrm{~V}$.

\subsection{Device Optimization}

Silicon material is used for the fabrication of an optimized FinFET device with a physical gate length of $15 \mathrm{~nm}$. $\mathrm{TiO}_{2}$ is used as gate dielectric material to replace $\mathrm{HfO}_{2}$ for better controllability of the gate over the channel. As it is well-known, the electrostatic integrity can be improved by reducing the thickness of the gate oxide [26]. The high-k dielectric thickness is chosen to be $2 \mathrm{~nm}$. Based on the previous investigation, the fin width and fin height are chosen to be equal to $4 \mathrm{~nm}$ and $35 \mathrm{~nm}$, respectively. Fin width was scaled down in order to improve FinFET electrostatics. The source/drain spacers are fixed to $7 \mathrm{~nm}$ and covered by $\mathrm{Si}_{3} \mathrm{~N}_{4}$. The contact resistivity at the S/D contact/silicon interface is fixed to $10^{-9} \Omega . \mathrm{cm}^{2}$. The proposed device with the above characteristics shows a good improvement in electrical parameters such as $I_{o n}, S S$, and DIBL compared to calibrated FinFET [1]. This proves that the improvement of SCEs in the FinFET device reduces sensitivity to the leakage current. It is also interesting to note that $I_{o n} / I_{\text {off }}$ ratio is approximatively two times greater than the calibrated FinFET. Better device switching (on/off) can result from steeping $S S$ and a larger $I_{\text {on }} / I_{\text {off }}$ ratio. Table 3 illustrates a comparison of the optimized and calibrated device parameters with different 14-nm FinFET device technologies [28-30].

Table 3. Comparison of different 14-nm SOI n-FinFET device technologies.

\begin{tabular}{|c|c|c|c|c|c|}
\hline $\begin{array}{c}\text { Device } \\
\text { Characteristics }\end{array}$ & $\begin{array}{c}\text { Calibrated } \\
\text { Device }\end{array}$ & $\begin{array}{c}\text { Optimized } \\
\text { Device }\end{array}$ & $\begin{array}{c}\text { FinFET } \\
{[28]}\end{array}$ & $\begin{array}{c}\text { FinFET } \\
\text { (IRDS 2020) } \\
\text { [29] }\end{array}$ & FinFET [30] \\
\hline$V_{d d}(\mathrm{mV})$ & 800 & 800 & - & - & - \\
\hline$V_{\text {th, } \operatorname{lin}}(\mathrm{mV})$ & 137.31 & 143.6 & - & - & - \\
\hline$V_{\text {th, sat }}(\mathrm{mV})$ & 120 & 110.5 & - & 240 & 233.55 \\
\hline$I_{o n, \operatorname{lin}}(\mu \mathrm{A})$ & 8.11 & 17.49 & - & - & - \\
\hline$I_{\text {on, sat }}(\mu \mathrm{A})$ & 53.6 & 148.93 & - & 68.62 & $10.9(/ \mu \mathrm{A})$ \\
\hline$I_{o f f}$, lin $(\mathrm{nA})$ & 1.89 & 1.89 & - & - & - \\
\hline$I_{o f f, \text { sat }}(\mathrm{nA})$ & 4.22 & 5.35 & - & 1.76 & $80.6(/ \mu \mathrm{A})$ \\
\hline$I_{o n}$, lin $/ I_{o f f, l i n}$ & $4.29 \times 10^{3}$ & $9.24 \times 10^{3}$ & - & - & - \\
\hline$I_{o n, \text { sat }} / I_{\text {off, sat }}$ & $1.27 \times 10^{4}$ & $2.77 \times 10^{4}$ & - & 38.933 & 135.236 \\
\hline$S S_{\text {lin }}(\mathrm{mV} / \mathrm{dec})$ & 60.60 & 58.80 & 80 & - & - \\
\hline$S S_{\text {sat }}(\mathrm{mV} / \mathrm{dec})$ & 64.91 & 58.22 & - & 72 & 76.98 \\
\hline$D I B L(\mathrm{mV} / \mathrm{V})$ & 43.32 & 22.65 & 75 & 50 & 68.57 \\
\hline
\end{tabular}

Finally, it should be highlighted that nowadays the interest for the FinFET technology is spreading more and more in many fields of application-such as single-molecule detection [31], pH sensing [32,33], biomedicine [34], label-free biosensing [35], 5G power 
amplifiers [36], energy harvesting [37], and space application [38], just to mention a few. This wide and ever-expanding range of applications makes evident the increasing need for an accurate optimization of the FinFET structure to satisfy the specific constraints and requirements.

\section{Conclusions}

In this study, the 3D 14-nm SOI n-FinFET was successfully simulated, performed, and calibrated to experimental data by using Silvaco tools. The effects of varying the fin width, fin height, gate dielectric material, and gate length on device performance were analyzed in terms of both DC and RF parameters. The results indicated that low leakage current and high $I_{o n} / I_{\text {off }}$ ratio can be obtained with small $W_{\text {fin }}$ and $H_{\text {fin }}$. A cut-off frequency on the order of $1 \mathrm{THz}$ was simulated and reported for the investigated FinFET model. The results indicated that this frequency is increased for smaller fin width and a subsequent reduction of gate transconductance. For the optimized device, a transconductance of $69.33 \mu \mathrm{S}$ and a cut-off frequency of $4.22 \mathrm{THz}$ were achieved at $V_{d s}=0.05 \mathrm{~V}$ with $V_{g s}=0.23 \mathrm{~V}$ and $V_{g s}$ $=0.22 \mathrm{~V}$, respectively, by using the $\mathrm{TiO}_{2}$ as the gate dielectric at $15-\mathrm{nm}$ gate length. The developed study provided some useful insights outlining the great potential of the FinFET technology nodes for RF applications with high performance and low power consumption.

Author Contributions: Conceptualization, N.E.I.B.; Methodology, N.E.I.B.; Software, N.E.I.B.; Validation, N.E.I.B., T.R.L. and S.P.; Investigation, N.E.I.B.; Writing—original draft preparation, N.E.I.B.; Writing-review and editing, S.P. and G.C.; Supervision, S.P. and G.C. All authors have read and agreed to the published version of the manuscript.

Funding: This research received no external funding.

Acknowledgments: This work was partially supported by Semiconductor Laboratory (GE01/08), Kuwait University.

Conflicts of Interest: The authors declare no conflict of interest. The funders had no role in the design of the study; in the collection, analyses, or interpretation of data; in the writing of the manuscript, or in the decision to publish the results.

\section{References}

1. Lin, C.H.; Greene, B.; Narasimha, S.; Cai, J.; Bryant, A.; Radens, C.; Narayanan, V.; Linder, B.; Ho, H.; Aiyar, A.; et al. High performance 14nm SOI FinFET CMOS technology with $0.0174 \mu \mathrm{m} 2$ embedded DRAM and 15 levels of Cu metallization. In Proceedings of the 2014 IEEE International Electron Devices Meeting, San Francisco, CA, USA, 15-17 December 2014; pp. 3-8.

2. Sun, J.; Li, X.; Sun, Y.; Shi, Y. Impact of geometry, doping, temperature, and boundary conductivity on thermal characteristics of 14-nm bulk and SOI FinFETs. IEEE Trans. Device Mater. Reliab. 2020, 20, 119-127. [CrossRef]

3. Kumar, U.S.; Rao, V.R. A thermal-aware device design considerations for nanoscale SOI and bulk FinFETs. IEEE Trans. Electron Devices 2015, 63, 280-287. [CrossRef]

4. Jena, K.; Swain, R.; Lenka, T.R. Effect of thin gate dielectrics on DC, radio frequency and linearity characteristics of lattice-matched AlInN/AlN/GaN metal-oxide-semiconductor high electron mobility transistor. IET Circuits Devices Syst. 2016, 10, 423-432. [CrossRef]

5. Mishra, S.; Parihar, N.; Anandkrishnan, R.; Dabhi, C.K.; Chauhan, Y.S.; Mahapatra, S. NBTI-related variability impact on 14-nm node FinFET SRAM performance and static power: Correlation to time zero fluctuations. IEEE Trans. Electron Devices 2018, 65, 4846-4853. [CrossRef]

6. Boukortt, N.; Patanè, S.; Crupi, G. 3D investigation of 8-nm tapered n-FinFET model. Silicon 2020, 12, 1585-1591. [CrossRef]

7. Boukortt, N.; Hadri, B.; Patanè, S.; Caddemi, A.; Crupi, G. Investigation on TG n-FinFET parameters by varying channel doping concentration and gate length. Silicon 2017, 9, 885-893. [CrossRef]

8. Yoon, J.-S.; Baek, R.-H. Device Design Guideline of 5-nm-Node FinFETs and Nanosheet FETs for Analog/RF Applications. IEEE Access. 2020, 8, 189395-189403. [CrossRef]

9. Boukortt, N.; Hadri, B.; Patanè, S.; Caddemi, A.; Crupi, G. Electrical Characteristics of 8-nm SOI n-FinFETs. Silicon 2016, 8, 497-503. [CrossRef]

10. Boukortt, N.E.I.; Hadri, B.; Caddemi, A.; Crupi, G.; Patane, S. 3-D Simulation of Nanoscale SOI n-FinFET at a Gate Length of 8 nm Using ATLAS SILVACO. Trans. Electr. Electron. Mater. 2015, 16, 156-161. [CrossRef]

11. Boukortt, N.E.I.; Hadri, B.; Caddemi, A.; Crupi, G.; Patane, S. Temperature Dependence of Electrical Parameters of Silicon-onInsulator Triple Gate n-Channel Fin Field Effect Transistor. Trans. Electr. Electron. Mater. 2016, 17, 329-334. [CrossRef] 
12. Natarajan, S.; Agostinelli, M.; Akbar, S.; Bost, M.; Bowonder, A.; Chikarmane, V.; Chouksey, S.; Dasgupta, A.; Fischer, K.; $\mathrm{Fu}, \mathrm{Q}$; ; et al. A $14 \mathrm{~nm}$ logic technology featuring 2 nd-generation finfet, air-gapped interconnects, self-aligned double patterning and a $0.0588 \mu \mathrm{m} 2$ sram cell size. In Proceedings of the 2014 IEEE International Electron Devices Meeting, San Francisco, CA, USA, 15-17 December 2014; pp. 3-7.

13. User Guide Manual, ATLAS, Version 5.28.1.R USA; Silvaco Inc.: San Francisco, CA, USA, 2019.

14. Subramanian, V.; Parvais, B.; Borremans, J.; Mercha, A.; Linten, D.; Wambacq, P.; Loo, J.; Dehan, M.; Gustin, C.; Collaert, N.; et al. Planar Bulk MOSFETs Versus FinFETs: An Analog/RF Perspective. IEEE Trans. Electron. Devices 2006, 53, 3071-3079. [CrossRef]

15. Martinez-Lopez, A.G.; Cerdeira, A.; Tinoco, J.C.; Alvarado, J.; Padron, W.Y.; Mendoza, C.; Raskin, J.-P. RF modeling of 40-nm SOI triple-gate FinFET. Int. J. Numer. Model. 2015, 28, 465-478. [CrossRef]

16. Crupi, G.; Schreurs, D.M.P.; Caddemi, A. Effects of gate-length scaling on microwave MOSFET performance. Electronics 2017, 6, 62. [CrossRef]

17. Sreenivasulu, V.B.; Narendar, V. A comprehensive analysis of junctionless tri-gate (TG) FinFET towards low-power and highfrequency applications at 5-nm gate length. Silicon 2021, 1-13. [CrossRef]

18. Huang, S.E.; Yu, C.L.; Su, P. Investigation of fin-width sensitivity of threshold voltage for InGaAs and Si negative-capacitance FinFETs considering quantum-confinement effect. IEEE Trans. Electron Devices 2019, 66, 2538-2543. [CrossRef]

19. Colinge, J.P. Multiple-gate soi mosfets. Solid-State Electron. 2004, 48, 897-905. [CrossRef]

20. Kurniawan, E.D.; Yang, H.; Lin, C.C.; Wu, Y.C. Effect of fin shape of tapered FinFETs on the device performance in 5-nm node CMOS technology. Microelectron. Reliab. 2018, 83, 254-259. [CrossRef]

21. Thorp, J.S.; Evans, D.; Al-Naief, M.; Akhtaruzzaman, M. The dielectric properties of aluminium nitride substrates for microelectronics packaging. J. Mater. Sci. 1990, 25, 4965-4971. [CrossRef]

22. Gorchichko, M.; Cao, Y.; Zhang, E.X.; Yan, D.; Gong, H.; Zhao, S.E.; Wang, P.; Jiang, R.; Liang, C.; Fleetwood, D.M.; et al. Total-ionizing-dose effects and low-frequency noise in 30-nm gate-length bulk and SOI FinFETs with $\mathrm{SiO}_{2} / \mathrm{HfO}_{2}$ gate dielectrics. IEEE Trans. Nucl. Sci. 2019, 67, 245-252. [CrossRef]

23. Crupi, G.; Caddemi, A.; Schreurs, D.M.M.-P.; Wiatr, W.; Mercha, A. Microwave noise modeling of FinFETs. Solid-State Electron. 2011, 56, 18-22. [CrossRef]

24. Crupi, G.; Schreurs, D.M.M.-P.; Caddemi, A.; Angelov, I.; Homayouni, M.; Raffo, A.; Vannini, G.; Parvais, B. Purely analytical extraction of an improved nonlinear FinFET model including non-quasi-static effects. Microelectron. Eng. 2009, 86, $2283-2289$. [CrossRef]

25. Jin, X.; Ou, J.J.; Chen, C.H.; Liu, W.; Deen, M.J.; Gray, P.R.; Hu, C. An effective gate resistance model for CMOS RF and noise modeling. In Proceedings of the International Electron Devices Meeting 1998. Technical Digest (Cat. No.98CH36217), San Francisco, CA, USA, 6-9 December 1998; pp. 961-964.

26. Park, J.; Kim, J.; Showdhury, S.; Shin, C.; Rhee, H.; Yeo, M.S.; Cho, E.C.; Yi, J. Electrical Characteristics of Bulk FinFET According to Spacer Length. Electronics 2020, 9, 1283. [CrossRef]

27. Lee, K.L.; He, R.Y.; Huang, H.W.; Yeh, C.C.; Li, I.H.; Cheng, O. A study of fin width effect on the performance of FinFET. In Proceedings of the 2015 IEEE 22nd International Symposium on the Physical and Failure Analysis of Integrated Circuits, Hsinchu, Taiwan, 29 June-2 July 2015; pp. 503-504.

28. Zhang, J.; Niu, G.; Cai, W.; Imura, K. Comparison of PMOS and NMOS in a 14-nm RF FinFET technology: RF Characteristics and Compact Modeling. In Proceedings of the 2020 IEEE 20th Topical Meeting on Silicon Monolithic Integrated Circuits in RF Systems (SiRF), San Antonio, TX, USA, 26-29 January 2020; pp. 47-49.

29. Wang, G.; Qin, C.; Yin, H.; Luo, J.; Duan, N.; Yang, P.; Gao, X.; Yang, T.; Li, J.; Yan, J.; et al. Study of SiGe selective epitaxial process integration with high-k and metal gate for 16/14nm nodes FinFET technology. Microelectron. Eng. 2016, 163, 49-54. [CrossRef]

30. Mah, S.K.; Ker, P.J.; Ahmad, I.; Zainul Abidin, N.F.; Ali Gamel, M.M. A Feasible Alternative to FDSOI and FinFET: Optimization of W/ $\mathrm{La}_{2} \mathrm{O}_{3} / \mathrm{Si}$ Planar PMOS with 14 nm Gate-Length. Materials 2021, 14, 5721. [CrossRef]

31. Santermans, S.; Barge, D.; Hellings, G.; Mori, C.B.; Migacz, K.J.; Rip, J.; Spampinato, V.; Vos, R.; Du Bois, B.; Chaudhuri, A.R.; et al $50 \mathrm{~nm}$ Gate Length FinFET Biosensor \& the Outlook for Single-Molecule Detection. In Proceedings of the 2020 IEEE International Electron Devices Meeting (IEEE-IEDM), San Francisco, CA, USA, 12-18 December 2020; pp. 35.4.1-35.4.4.

32. Rani, D.; Rollo, S.; Olthuis, W.; Krishnamoorthy, S.; Pascual García, C. Combining Chemical Functionalization and FinFET Geometry for Field Effect Sensors as Accessible Technology to Optimize pH Sensing. Chemosensors 2021, 9, 20. [CrossRef]

33. Medina-Bailon, C.; Kumar, N.; Dhar, R.P.S.; Todorova, I.; Lenoble, D.; Georgiev, V.P.; García, C.P. Comprehensive Analytical Modelling of an Absolute pH Sensor. Sensors 2021, 21, 5190. [CrossRef]

34. Coluccio, M.L.; Pullano, S.A.; Vismara, M.F.M.; Coppedè, N.; Perozziello, G.; Candeloro, P.; Gentile, F.; Malara, N. Emerging Designs of Electronic Devices in Biomedicine. Micromachines 2020, 11, 123. [CrossRef] [PubMed]

35. Dixit, A.; Samajdar, D.P.; Chauhan, V. Sensitivity Analysis of a Novel Negative Capacitance FinFET for Label-Free Biosensing. IEEE Trans. Electron Devices 2021, 68, 5204-5210. [CrossRef]

36. Daneshgar, S.; Dasgupta, K.; Thakkar, C.; Chakrabarti, A.; Levy, C.S.; Jaussi, J.E.; Casper, B. High-Power Generation for mm-Wave 5G Power Amplifiers in Deep Submicrometer Planar and FinFET Bulk CMOS. IEEE Trans. Microw. Theory Tech. 2020, 68, 2041-2056. [CrossRef] 
37. Whittaker, K.; Rizkalla, M.; Ytterdal, T. A Low Power FinFET Charge Pump for Energy Harvesting Applications. In Proceedings of the 2020 IEEE 63rd International Midwest Symposium on Circuits and Systems (MWSCAS), Springfield, MA, USA, 9-12 August 2020; pp. 1048-1051. [CrossRef]

38. Cai, C.; Gao, S.; Zhao, P.; Yu, J.; Zhao, K.; Xu, L.; Li, D.; He, Z.; Yang, G.; Liu, T.; et al. SEE Sensitivity Evaluation for Commercial 16 nm SRAM-FPGA. Electronics 2019, 8, 1531. [CrossRef] 